\title{
A cien años de la matanza de Forrahue: digna sepultura para los comuneros mapuches
}

One Hundred Years After the Slaughter at Forrahue:

A Respectful Burial for the Mapuche People

Cem anos após a matança de Forrahue: digna

sepultura para os comuneiros mapuches

\section{Rodrigo Cánovas}

PONTIFICIA UNIVERSIDAD CATÓLICA DE CHILE, CHILE

Ph.D. de The University of Texas at Austin. Entre sus principales publicaciones se encuentran: Literatura de inmigrante árabes y judíos en Chile y México (Iberoamericana Vervuert, 2011), Sexualidad y cultura en la novela hispanoamericana (Lom, 2003), y Novela chilena, nuevas generaciones (Pontificia Universidad Católica de Chile, 1997).Correo electrónico: rcanovas@uc.cl

\footnotetext{
Artículo de investigación

Proyecto de Investigación financiado por el Fondo Nacional de Ciencias de Investigación y Tecnología, Chile, FONDECYT N 1130002 (en proceso: 2013-1016), titulado "Relatos (auto) biográficos chilenos (1991-2011): nuevas y antiguas señas de identidad". El texto fue presentado como ponencia ("Actas chilenas del despojo") en el I Congreso Internacional de Literatura y Derechos Humanos, Universitá degli Studi de Milano, 29 junio-4julio de 2015.

Documento accesible en línea desde la siguiente dirección: http://revistas.javeriana.edu.co
} 


\section{Resumen}

Este artículo comenta el libro

Forrahue. Matanza de 1912, cuya autoría es de la comunidad indígena de Forrahue

(comunidad mapuche situada en el sur de Chile) y del escritor mapuche Bernardo Colipán. Es un texto testimonial, que se presenta como un escrito legal para restablecer la verdad en el ámbito del relato histórico y de la memoria nacional chilena. $\mathrm{Al}$ ser un texto que incluye diagramas, fotos y textos escritos en diversos tipos de letras, hemos incluido activamente este registro intermedial en la lectura e interpretación de este artefacto cultural. En el ámbito simbólico, el libro es el lugar donde los cuerpos sin sepultura descansan, permitiendo el luto de una comunidad.

Palabras clave: derechos humanos; grupo étnico; Chile; Estado nación; Mapuche

\section{Abstract}

This paper reviews Forrahue. Matanza de 1912, written by the Mapuche writer Bernardo Colipán and co-authored with the Forrahue indigenous community located in Southern Chile. The book is a testimonial text that acts as a legal document and seeks to restore the truth in the context of Chile's historical account and collective memory. This text includes diagrams, photos and fragments in various types of handwriting, which we consider relevant in the reading and interpretation of this cultural artifact. From a symbolic perspective, the book is the place where the unburied bodies rest, allowing both the Chilean and Mapuche communities to mourn.

Keywords: Human Rights; Ethnic Group; Chile; Nation-state; Mapuche

\section{Resumo}

Este artigo comenta o livro Forrahue. Matanza de 1912 sob a autoria da Comunidade Indígena Forrahue (comunidade mapuche localizada no sul do Chile) e do escritor mapuche Bernardo Colipán. É um texto testemunhal apresentado como escrito legal para restaurar a verdade no âmbito do relato histórico e da memória nacional chilena. Sendo um texto que inclui diagramas, fotos e textos escritos em diversos tipos de letras, incluímos ativamente este registro intermidial na leitura e interpretação deste artefato cultural. No âmbito simbólico, o livro é o lugar onde os corpos sem sepultura descansam, permitindo o luto de una comunidade.

\section{Palavras-chave: Direitos} Humanos; grupo étnico; Chile; Estado nação; Mapuche 
UNO DE LOS relatos que vertebra la apertura de este nuevo siglo en Chile es el relato de nuestras vidas, asociado a los parajes del yo, de la familia y de las comunidades. En esta oportunidad, queremos centrarnos en un tipo de biografías comunitarias que llevan la marca de lo vernáculo y que están en el corazón de nuestra todavía joven república de Chile: son las biografías indígenas y en este caso particular, una biografía mapuche (particularmente, huilliche) que instala en la memoria republicana un hecho extraviado en los archivos oficiales: la matanza de al menos 13 comuneros en 1912 en la zona de Forrahue, cercana a la ciudad de Osorno, en el sur de Chile (Colipán y comunidad indígena de Forrahue). ${ }^{1}$ A pesar de que tal matanza fue gran noticia en los periódicos de la región, de que hubo una investigación judicial y de que mereció ser puesta en tabla en una sesión del Senado de Chile, esta fue catalogada finalmente como un hecho policial, que durante los siguientes años fue arrancado de raíz de los anales de Osorno, lugar habitado principalmente por inmigrantes alemanes, criollos y mapuches-huilliches. ${ }^{2}$

La historia es simple: cumpliendo una orden de desalojo, un contingente policial fuertemente armado exige a un grupo de comuneros mapuches que abandonen su territorio y sus viviendas. Estamos en Forrahue, lugar matriz milenario de clanes familiares que ese día esperan a

1 Este libro no tiene sello editorial y sus páginas no están numeradas. Por ello, cada vez que lo citemos, pondremos s/n (es decir, sin numeración de página). Consideramos que uno de los rasgos singulares que permite la trascendencia cultural de este texto -además de su mensaje escrito- es su diagramación. Anotemos aquí los nombres de los diseñadores y fotógrafos, tal como aparecen en los créditos del libro. Diseño: Francisco Sáez, María José Villanueva y Patricia Zúñiga, quien lideró este trabajo. Fotografía: Mario Mendoza, María José Villanueva.

2 Teniendo en cuenta la identidad territorial, en la cultura mapuche distinguimos las comunidades costeras (lafkenche), cordilleranas (pehuenches) y sureñas (huilliches). La ciudad de Osorno y cercano a ella, el sector rural conocido como Forrahue, se ubican en la Región de los Lagos (X región, en el sur de Chile). En esta región conviven las comunidades huilliches, germanas, hispano-criollas y de bordemar (Colipán "Identidades, memoria y alegorías"). 
los uniformados, parapeteados en sus casas, dispuestos a resistir. Según el conteo oficial, el armamento huilliche en la primera casa, donde se concentraba la mayoría de los comuneros, era el siguiente: "4 escopetas, un rifle, siete cuchillos, una lanza antigua, tres machetes, dos hechonas, un hacha, un fierro largo, un martillo y cuarenta y tres garrotes" (Colipán y comunidad indígena de Forrahue s/n). Alrededor de esta primera casa se agrupaban mujeres y niños provistos de garrotes, y adentro había grupos de mujeres con tiestos de agua hirviendo, listas para repeler el ataque policial. Resultado final: 13 comuneros muertos, entre ellos un niño de 11 años, y dos sobrevivientes, alcanzados por balas del moderno fusil máuser, emblema del orden moderno republicano. Los cadáveres nunca fueron entregados a los familiares y se supone que fueron enterrados en una fosa común en el cementerio de la ciudad.

\section{Un libro sobre Forrahue: una obra de arte textil}

A cien años de estos hechos y habiendo ya algunas investigaciones académicas recientes sobre lo sucedido, aparece por primera vez un libro escrito desde una voz comunitaria indígena, con la coautoría de Bernardo Colipán, poeta y profesor nacido en esa zona.

¿Qué tipo de libro es este, cuál su composición, qué memoria concibe y rescata? Por lo pronto, desde el título-Forrahue. Matanza de 1912- se corrigen las actas oficiales: fue una matanza; y en sus páginas interiores, la lista de fallecidos es nombrada como una lista de hermanos asesinados. Situado en el ámbito del discurso testimonial, una voz colectiva indígena aparece condensada en uno de sus representantes, Bernardo Colipán, que opera como hacedor de un artefacto cultural que permite devolver la memoria tanto a su comunidad como a los chilenos.

Lo primero que sorprende en este libro es su diagramación, que lo incluye en la serie cultural de objetos artísticos, válidos por sus imágenes, colores, sensaciones, tipos de letras y trabajos con la página. Objeto en claroscuro, llama al recogimiento y sagrado silencio. Repasemos visualmente este libro, comenzando con los comentarios de la portada y de la contraportada (figuras 1 y 2). 


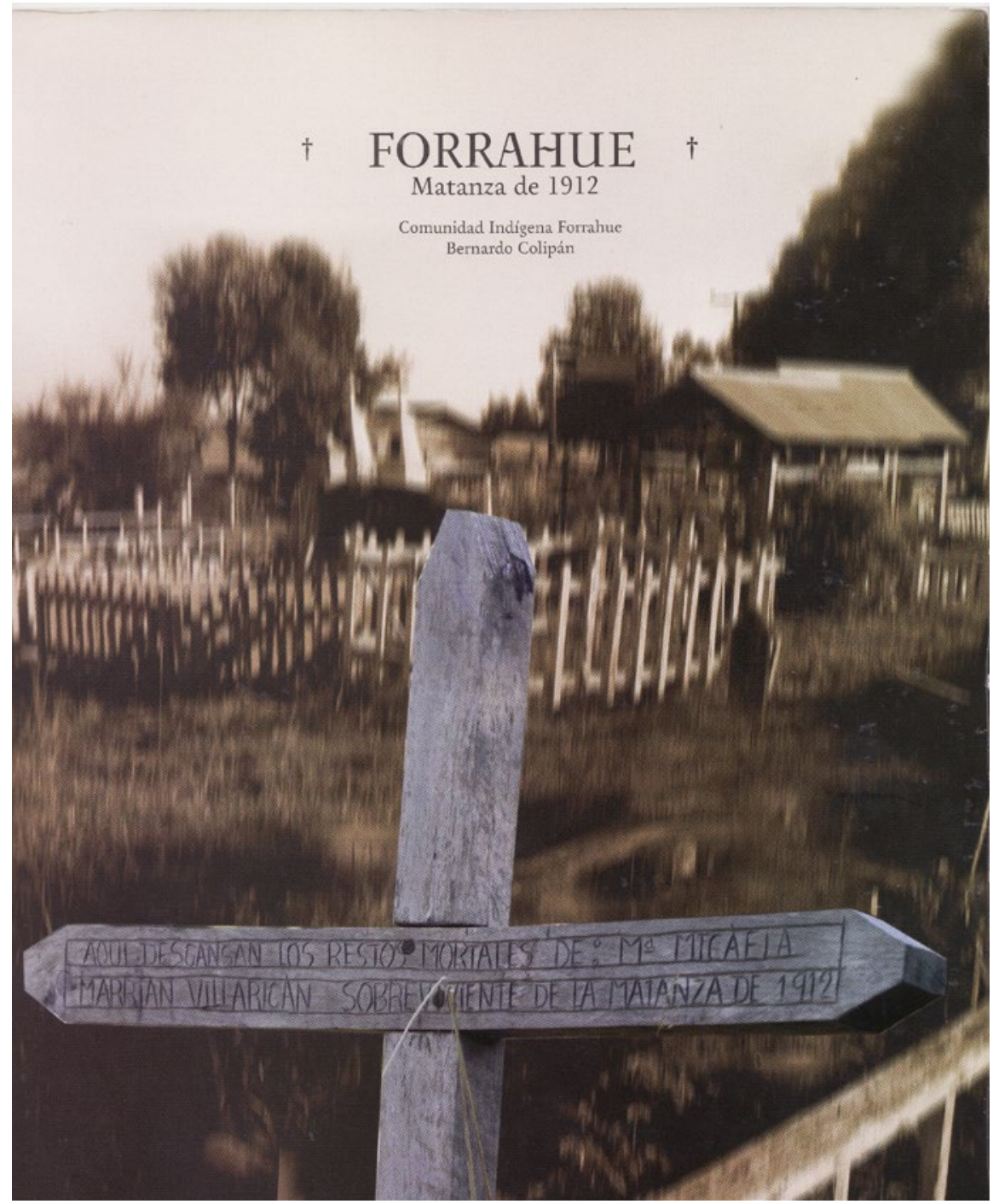

Figura 1. Portada

Fotografía: Mario Mendoza. Montaje: Patricia Zúñiga.

Fuente: Colipán y comunidad indígena de Forrahue. 


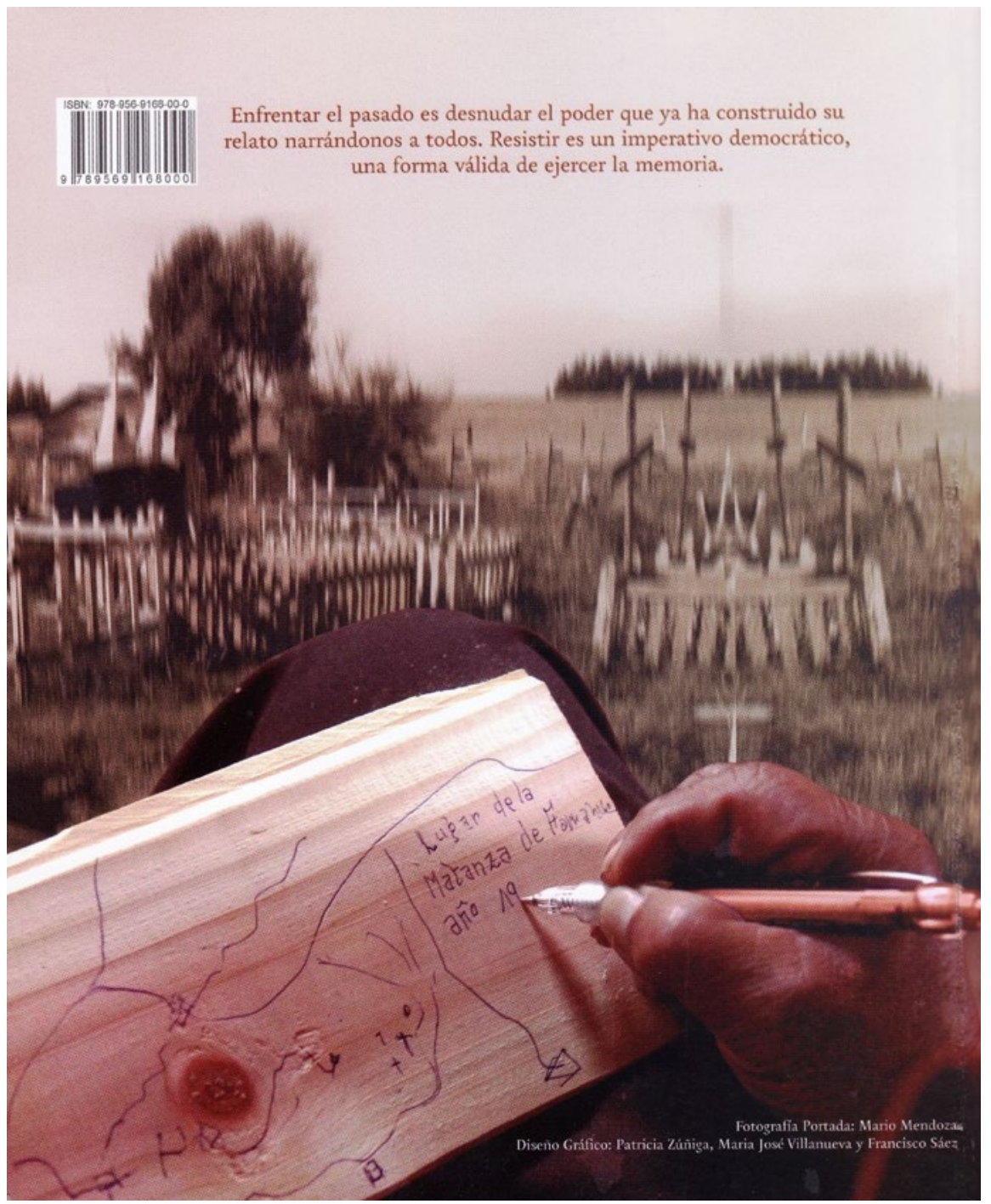

Figura 2. Contraportada

Fotografía: Mario Mendoza. Montaje: Patricia Zúñiga.

Fuente: Colipán y comunidad indígena de Forrahue. 
La portada exhibe una foto de un cementerio local semiabandonado de la zona de Forrahue, al cual se le ha superpuesto en primer plano una cruz de madera con la leyenda "Aquí descansan los restos mortales de: Ma. Micaela Marrian Villarican sobreviviente de la matanza de 1912". Presidiendo un paisaje desenfocado o en segundo plano, la cruz está retocada con un color plomizo, como de hueso. Por su parte, en las empalizadas de madera que rodean las sepulturas y evocan agrupaciones de cruces hacia el cielo, aparece inscrito el título: Forrahue. Matanza de 1912, acompañado a ambos lados por una pequeña crucecita. Y debajo del título, la autoría: comunidad indígena de Forrahue. Bernardo Colipán.

La contraportada exhibe una foto del mismo cementerio, de seguro el mismo lugar ya fotografiado, pero con diversa perspectiva o corrido unos metros, al cual se ha superpuesto en primer plano, en un montaje deliberadamente artificioso, un madero sobre el cual un campesino indígena escribe y hace trazos. En una versión realista, suponemos que el campesino está sentado en el suelo y sostiene sobre una de sus piernas flectadas un pedazo de madera que se asemeja a una hoja gruesa de papel (una especie de papiro huilliche), donde ha trazado un mapa básico (hay unas crucecitas juntas, líneas de separación de territorio y una flecha). Su mano ya ha diseñado con un lápiz de pasta brillante azul las líneas del territorio y ahora escribe: "lugar de la Matanza de Forrahue año 19" y en ese momento se obtura el ojo de la cámara. Esto es abajo, en la tierra, donde en letra chica se indican los nombres de los fotógrafos y diseñadores gráficos, también copartícipes en esta empresa (ninguno de ellos ostenta nombres mapuches). Arriba, en el cielo, leemos: "Enfrentar el pasado es desnudar el poder que ya ha construido su relato narrándonos a todos. Resistir es un imperativo democrático, una forma válida de ejercer la memoria".

Baste esta descripción básica del registro visual de la portada y la contraportada, para realizar algunos comentarios centrales sobre la función que cumple este libro en la sociedad chilena y en la comunidad mapuche.

En el espacio semiabandonado y anónimo de un cementerio local en medio de una naturaleza muda, aunque presente y armónica, aparece en primer plano la cruz de alguien que sobrevivió a la matanza y sí tuvo digna sepultura en su tierra de origen. Es una sinécdoque, la parte por el todo, una cruz que reúne los huesos de todos los ausentes; y también, una condensación temporal, en cuanto la sepultura de Micaela se retrotrae en el tiempo incluyendo la fecha de la muerte de sus hermanos. Se imbrican 
así, en un montaje, presente y pasado. No habiendo cuerpos, contándose con pequeñas empalizadas con cruces (casitas o patios de muertos), el libro se erige como espacio sustituto de recogimiento a visitar. En este contexto, la crucecita puesta a cada lado del título actúa como manilla de un féretro o acompaña como dibujo emblemático el título del frontón de un supuesto camposanto, siendo las páginas del libro sus sitios emblemáticos; en vez del descampado natural, el signo del libro que lo va a restituir, manteniendo en su fachada las marcas del abandono. ${ }^{3}$

En la contraportada, en un giro arqueológico, la mano mapuche hace un levantamiento del lugar, como si se fuera a emprender una excavación. Recordemos que Forrahue significa lugar de osamentas, es decir, una matriz original que sostiene a todo un clan desde tiempos muy remotos. Siniestramente, es aquí donde se sacrificaron muchos cuerpos huilliches y es a este sector donde esas nuevas osamentas deben regresar; aunque en realidad, desde el signo del libro, ya han regresado. Entremos entonces a este espacio construido como una imagen cósmica.

En un prolegómeno firmado por Bernardo Colipán desde Xochimilco, México y fechado en el año 2012, se nos indica cómo este libro pretende erigirse como soporte viviente de una memoria compartida por el pueblo mapuche.

Escrito en primera persona plural, desde un nosotros (aunque firmado por Colipán, sin renunciar a una clara marca de individualidad), el texto se plantea la tarea de la elaboración constante de la memoria desde parámetros propios de la comunidad, único modo de descubrir una identidad ligada a lazos primordiales, a saber: el apego a los sentimientos de lazos de sangre, etnia, lengua, región, religión y costumbres, sentimientos primordiales que entran en contradicción con los sentimientos civiles instituidos por las repúblicas modernas, que proponen otros contratos sociales. ${ }^{4}$

El cementerio de Forrahue se convirtió en monumento histórico en el año 2014. Actualmente el cementerio pertenece a y es administrado por la comunidad huilliche local. Cf. información de página web del Consejo de Monumentos Nacionales de Chile, donde se hace expresa mención a la matanza de 1912: http://www.monumentos. $\mathrm{cl} /$ catalogo/625/w3-article-39481.html

4 La noción de apego primordial (o lazos primordiales) ha sido propuesta por Clifford Geertz, en el contexto del surgimiento de nuevos estados después de la segunda guerra mundial en diversas regiones africanas y asiáticas: "Por apego primordial se entiende el que procede de los hechos 'dados' [...] de la existencia social: la contigüidad inmediata y las conexiones de parentesco principalmente, pero además 
La imagen central de la constitución de la memoria es la del telar mapuche:

Acudimos a la metáfora del trarikan y enhebramos las ideas, recuerdos y emociones, como se trabaja en el arte textil mapuche. Una hebra de lana se va cruzando con otra, formando un complejo tejido de sentidos, colores y emociones.

Lo hicimos pensando en el makun (manta) que algún día vestiremos y nos habitará.

En el trarikan lo importante, más que el recuerdo aislado, es la asociación de los recuerdos en un solo tejido. (Colipán y comunidad indígena de Forrahue s/n)

Trasladada esta imagen a la composición del libro, este se diagrama desde el entrelazamiento de textos escritos con distintos tipos de letras y con fotos, dibujos, colores y canciones que evocan sensaciones táctiles, sonoras y visuales. Son materiales diversos, que se van tejiendo, hasta lograr nuevamente lo uno indiviso. Operación de montaje que parte de lo fragmentario para reconstituir en una sola pieza el cuerpo huilliche, pues

los hechos dados que suponen el haber nacido en una particular comunidad religiosa, el hablar de una determinada lengua o dialecto de una lengua y el atenerse a ciertas prácticas sociales particulares. Estas igualdades de sangre, habla, costumbre, etc., se experimentan como vínculos inefables, vigorosos y obligatorios en sí mismos" (222). El conflicto entre los sentimientos civiles que rigen los nuevos estados y los sentimientos primordiales son de muy difícil resolución. Desde la perspectiva del espíritu de las nuevas naciones, estos apegos primordiales reciben las nominaciones de tribalismo, parroquialismo, comunalismo y otras. En el ámbito de los estudios sobre el pueblo mapuche y su relación con la república de Chile, varios historiadores han acudido a esta noción de Geertz, como por ejemplo José Bengoa en su "Encontrando la identidad en la celebración de la diversidad" (2003). En principio, la concepción de la identidad mapuche, especialmente enunciada desde voces vernáculas, está concebida desde este apego primordial. Así, oponiendo una identidad colectiva a una identidad diseñada, Eugenio Alcamán indica: "La identidad colectiva se funda en lazos naturales previamente constituidos entre sus miembros identificados (consanguineidad, idioma, historia, costumbres)" (444). Por cierto, el libro sobre Forrahue está sustentado sobre este principio. 
el trauma es aquí la partición de la memoria, la pérdida de un eje central ligada a los lazos primordiales. ${ }^{5} \mathrm{El}$ trabajo de la memoria es de restauración: las generaciones futuras van colmando los vacíos, levantando las censuras, llorando a sus muertos. Es, entonces, una memoria del porvenir que debe coincidir con la memoria de los orígenes.

Desde la metáfora del telar, podemos distinguir y celebrar cada parte del libro, que cobra su sentido pleno cuando la enredamos con las otras partes, generándose nuevos dibujos y diseños. Nombremos estas secciones, que se van combinando en el constante ejercicio de hojear el libro, yendo y viniendo, haciéndolo circular continuamente.

Al prolegómeno autorial, escrito desde Xochimilco (punto simbólico de referencia para un nuevo mapa indígena americano, donde ya se enuncia en el sur a Forrahue), le sigue una parte histórica -titulada "Forrahue. Lugar de memoria y osamentas a contraluz"-, donde se realiza una crónica de los hechos ocurridos, y se recrean sus contextos. Escrito a modo de actas, autorizadas por documentos y testimonios orales, se enuncia desde una polémica abierta con los archivos oficiales de la nación. ${ }^{6}$

En la siguiente sección, denominada "Genealogía de la vida", se diagraman las genealogías de los asesinados y sobrevivientes, dibujándose semicírculos (y no las figuras prototípicas de los árboles), aludiendo -según nuestra lectura- a la figura circular del cultrún, emblema del orden cósmico mapuche (figuras 3 y 4). Las páginas tienen el color de la sangre.

5 En el prolegómeno, se establece una relación directa entre la identidad fragmentada y la instauración del latifundio como fundamento de la economía nacional: "La fragmentación que el latifundio hizo de nuestros territorios, provocó en nosotros una fragmentación de nuestra memoria colectiva. La violencia del latifundio, se dirigió esencialmente a disociar el küpan [linaje, clan familiar] de nuestro tuwun [lof: territorio, lugar de origen donde se asienta el clan familiar] y de convertirnos en seres sin vínculos, sin espacio y sin tiempo" (Colipán y comunidad indígena de Forrahue s/n).

6 Acudimos aquí a la noción bajtiniana polémica abierta, para enfatizar que este discurso toma dos direcciones: hacia un referente y hacia el discurso de otro. En esta circunstancia particular, el discurso de otro (oficial, normativo, censurador, al lado de la ley) queda fuera del discurso de la palabra del autor; pero este lo toma en cuenta y se relaciona con él desde la refutación. Esta descalificación plena tiene su explicación en el poder sancionador que detenta el discurso de otro en la materia social discutida (Todorov "Intertextuality"). 


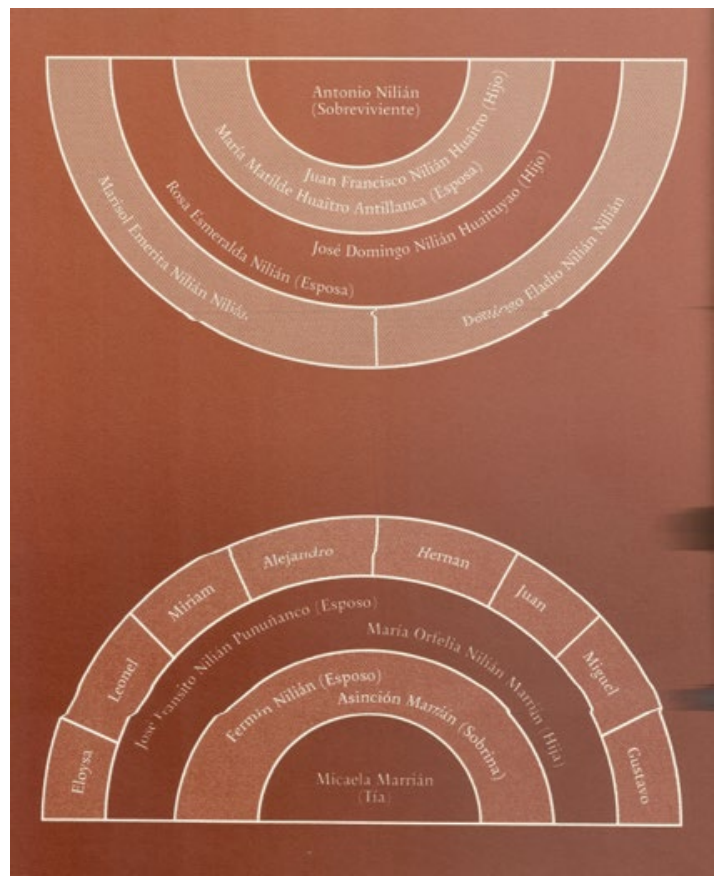

Figura 3. Genealogía de la vida

Fotografía: Patricia Zúñiga y equipo.

Fuente: Colipán y comunidad indígena de Forrahue.

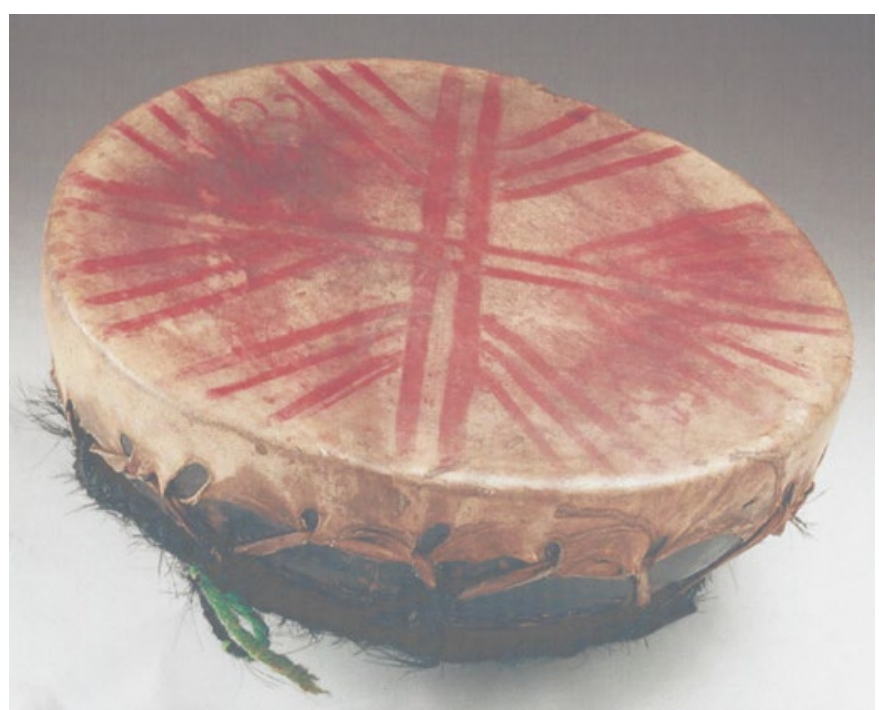

Figura 4. Kultrún

Fotografía: Museo de Arte Precolombino. 
A estos mapas de filiaciones le sigue la lista de difuntos (titulada Hermanos), que precede a una serie de certificados oficiales de defunción de los asesinados, logrados en el año 2011; documentos que visibilizan estos cuerpos en el presente, devolviéndoles una identidad legal interdicta (gente anónima arrojada a la fosa común) y que, con ello, los reinsertan en el ánimo chileno (figuras 5 y 6).

$$
\begin{aligned}
& \text { Hermanos } \\
& \text { Asesinados } \\
& \text {. Antonio Treimul } \\
& \text {. José María Panguinao } \\
& \text {. Francisco Treimul } \\
& \text { Tránsito Quintul } \\
& \text { Carmen Panguinao } \\
& \text {. Carmen Llaitul } \\
& \text {. Carolina Guimay } \\
& \text {. Angela Rauque } \\
& \text {. Candelaria Panguinao } \\
& \text {. Candelaria Colil } \\
& \text {. Antonio Nilián } \\
& \text {. Juan Acum } \\
& \text {. Juana María Quintul } \\
& \text { Heridos y reos } \\
& \text {. Antonio Treimul } \\
& \text {. José María Panguinao } \\
& \text {. Francisco Treimul } \\
& \text { Tránsito Quintul } \\
& \text {. Carmen Panguinao } \\
& \text {. Carmen Llaitul } \\
& \text { Carolina Guimay } \\
& \text {. Angela Rauque } \\
& \text { Candelaria Panguinao } \\
& \text {. Candelaria Colil } \\
& \text {. Antonio Nilián } \\
& \text {. Juan Acum } \\
& \text {. Juana María Quintul } \\
& \text { Sobrevivientes } \\
& \text {. Pedro José Acum } \\
& \text {. Micalea Marrián }
\end{aligned}
$$

Figura 5. Hermanos

Fotografía: Patricia Zúñiga y equipo.

Fuente: Colipán y comunidad indígena de Forrahue. 


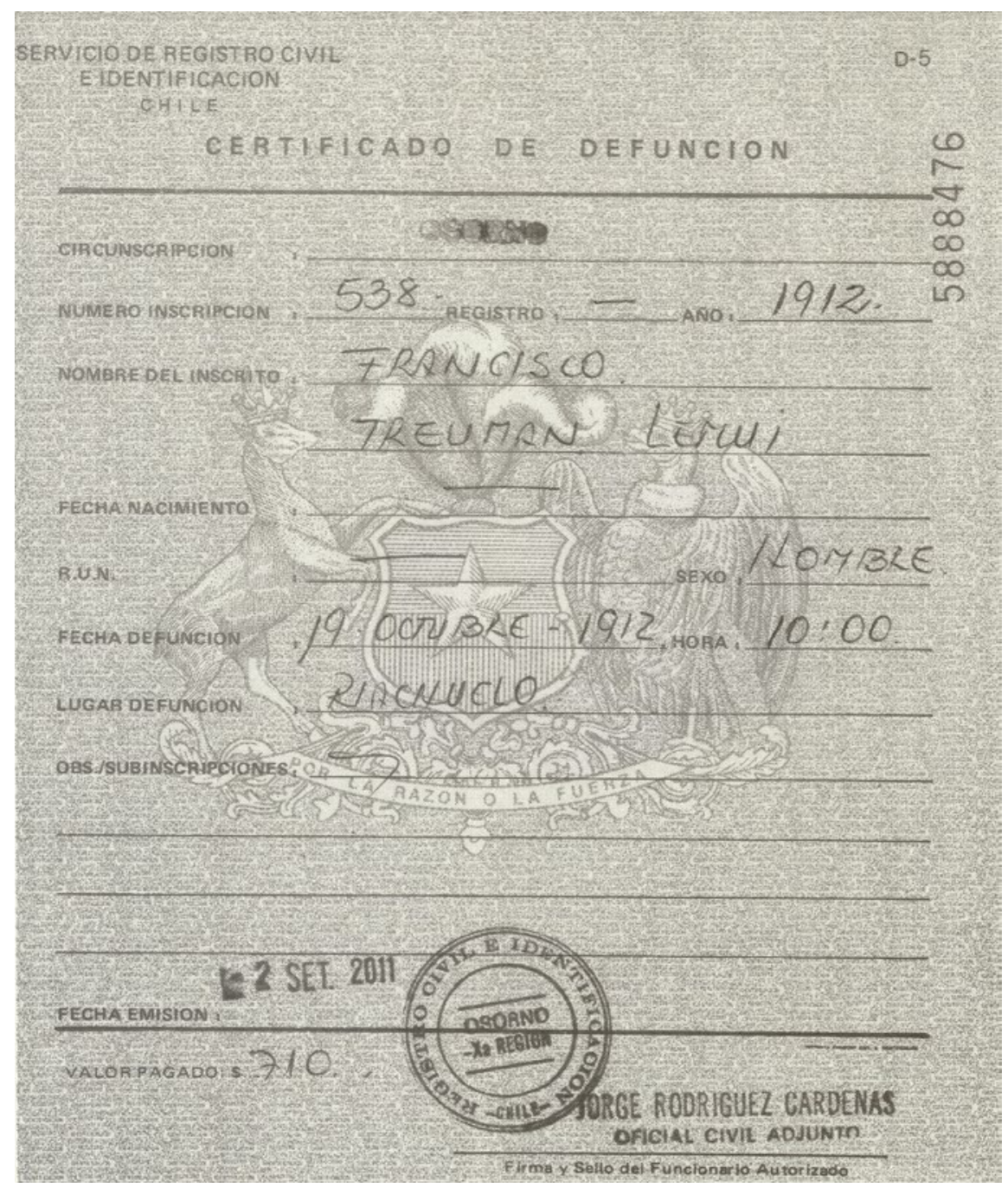

Figura 6. Certificado de defunción de Francisco Treuman Lemui Fotografía: Patricia Zúñiga y equipo.

Fuente: Colipán y comunidad indígena de Forrahue.

Por último, está la sección de los testimonios de los familiares de la tercera y cuarta generación, que son presentados bajo titulares destacados, semejando la página de un diario o de un folleto comunitario realizado artesanalmente (figura 7). 
esto". Después a ellos les pilló la noche y se fueron a alojar donde un vecino, esperando a sus compañeros si llegaban o no; fue triste -dicen ellos- muy triste y en unas de esas, que llegó el esposo, el papá de mi abuelita, llegó donde estaba su mamá, y llegó vivo. El se llamaba José María y el yerno, el esposo de mi abuelita también se llamaba José María y su suegro también se llamaba José María y también era Nilián, ya entonces que dijo: "el muerto es Vicente, el dueño de la tierra, el que tenía la escritura:

Vicente Paillán. Dice mi abuela que, unos no pudieron más con las heridas y que a otros que los amontonaban en carretas, los subían muertos, así los subian ella, fue a ver a su abuelo, más bien dicho a Vicente Paillán... y estaba muerto, todo herido, todo baleao, todo cortado con murreras, en estas partes de por aquí, le hicieron cortes y lo fueron a tirar a un cementerio moro, hoy en día está sembrado, barbechado, ahora hay un tremendo trigal, en esa subida del puente para arriba, ahí están nuestros abuelos sepultados, hoy los ricos barbecharon, ellos siempre lo hacen así.

Luisa Nilián, 70 años, Putica.

\section{Después de la matanza, ustedes, no tienen adonde vivir.}

Y entonces lo que pasó después, es que ellos no hallaron donde vivir. Así que tenian un tío, éste que dijo: "ustedes no tienen donde vivir, yo los voy a dejar aquí, en esta parte". Aquíllegaron dos, mi abuelita con su mamá, en verdad fueron tres, mi abuelita con su mamá, su papá y otra señora que se llamaba Florinda Nilián. Esa abuelita llegaron a arrinconarse acá po, hicieron un techito para poder vivir, eso es lo que conversaban ellos.
Siempre conversaba mi abuela de la desgracia decía: "ese fue el engaño que le hicieron a nuestra familia, fue muy triste, ellos se arrancaron con lo puesto no más".

Luisa Nilián, 70 años, Putica.

\section{Sólo quiero una flor, una vela siquiera un día, para recordarlo.}

i todavia, me da no se qué, porque siem-
pre cuando me acuerdo de mi abuela que
me decia: "así fue mi tierra, la tierra de noso-
tros la quitaron, por eso mi mamá quedó de
esa manera, quedó demente, porque nosotros

fuimos despojados. $\mathrm{Y}$ ahora mi tío está sepultado en tal parte o mi abuelo.

¡Ah!, ¿no es terrible?...

$\mathrm{Y}$ a mí me da no se qué, a veces cuando conversamos, yo le comento, a las que están aquí

Figura 7. Testimonios de los familiares de la tercera y cuarta generación Fotografía: Patricia Zúñiga y equipo.

Fuente: Colipán y comunidad indígena de Forrahue.

El libro cierra con un registro fotográfico muy intervenido de una gran cruz abandonada en medio de un sitio ya convertido en eriazo, en paralelo con una frase recortada a lo largo de tres páginas que dice: "El olvido es muerte" (figura 8). 


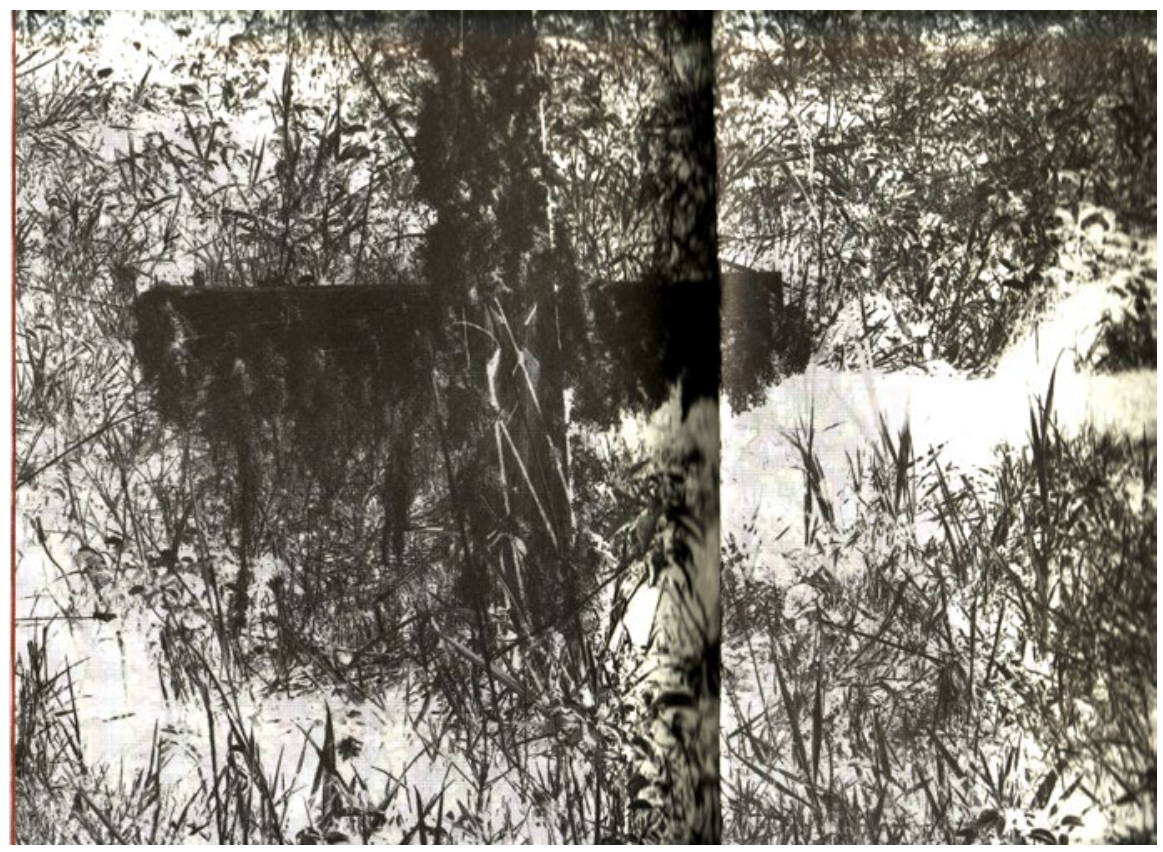

Figura 8. Cruz en sitio eriazo

Fotografía: Mario Mendoza, María José Villanueva, y Patricia Zúñiga y equipo.

Fuente: Colipán y comunidad indígena de Forrahue.

Libro-makun (libro-manto, que nos cubre), será experimentado en la comunidad de Forrahue como una memoria rescatada y en transformación, por su capacidad de generar nuevos pensamientos que seguirán fortaleciendo y densificando el tejido identitario. Libro también dispuesto para dar vueltas por la república de Chile, a modo de archivo correctivo de la nación.

Este telar de la memoria va ensamblando figuras emblemáticas que conforman una imaginación icónica, que fija imágenes mapuches que van reconfigurando la historia republicana, mostrando sus olvidos. Así, la imagen de la vergüenza de la república moderna chilena es la de tres niños de 12 años obligados a guiar carretas cargadas de heridos y moribundos comuneros del sitio de Forrahue. Fíjense aquí en el entrecruzamiento de los números: 3 de 12 en 1912, dispuestos a 100 años, en 2012. Como se señala en el texto, será "el primer momento en que la sociedad williche ingresa a la ciudad moderna [con comuneros de Forrahue] ejecutados por el máuser republicano" (Colipán y comunidad indígena de Forrahue s/n). 
A propósito del máuser moderno introducido a inicios del siglo XX en Chile, asociamos su imagen con la del lápiz de pasta moderno (con un gancho metálico estilizado) que aparece empuñado por una mano campesina en la foto superpuesta de la contraportada. Es como se hubiera sustituido una máquina de exterminio por un instrumento -una máquina que vomita tinta- que, estando en manos de los comuneros de Forrahue, puede ser un arma que entre a batallar en el orden de los signos para la recuperación de un lugar en esta tierra.

A continuación, haremos un repaso más detallado por las distintas partes de este libro, que se van entrecruzando para componer un signo cultural lumínico.

\section{Actas de un despojo: actas justas}

La sección que contiene el relato de los hechos se abre con un comentario contextual que hermana la matanza de Forrahue con la de la Escuela de Santa María de Iquique y el exterminio de los selknam en la zona austral de Chile, ocurridos en los inicios del siglo XX. Estas menciones históricas son relevantes, pues incluyen a la comunidad mapuche dentro de la república o en diálogo con ella, estableciendo un horizonte común con otros mundos (obreros del salitre, culturas patagónicas).

La misma publicación de ese libro, bajo el auspicio de la Corporación Nacional de Desarrollo Indígena, Conadi, con el logo correspondiente (que incluye el escudo de Chile con el cóndor y el huemul) dispuesto en la portadilla, es un signo de mediación, que debe interpretarse de doble manera: por un lado, Conadi interviene en el mundo indígena (ejerce control); pero al mismo tiempo es un canal de comunicación del mundo indígena para proteger su ideario en la nación donde aparece inserto. ${ }^{7}$

El relato comentado de la matanza lleva el título Actas de un despojo. De acuerdo al diccionario, la palabra acta, en su segunda acepción, es una certificación, testimonio o constancia oficial de un hecho; por lo cual consideramos que este escrito tiene una impronta legal, con posibilidades

\footnotetext{
"Las instituciones mediadoras [son aquellas] que desempeñan una función de control e intervención progresiva sobre la sociedad nativa y que, a su vez, cumplen labores de protección y representan instancias que permiten a los indígenas la conservación de espacios políticos propios dentro del Estado" (Vergara, citado en Foerster 422-423). Para una amplia reflexión sobre las corporaciones o institutos chilenos de asuntos indígenas ligados al Estado desde 1953, consúltese con provecho este mismo texto de Rolf Foerster.
} 
de ser usado en una corte judicial. De la relación de hechos, destacamos el uso de testigos de oídas en la actualidad (testimonios orales de familiares de la tercera y cuarta generación), la revisión de investigaciones recientes sobre la matanza y la situación indígena en el país, y el análisis discursivo del informe oficial emanado desde la gobernación de Osorno al Ministerio del Interior en octubre de 1912, que permite descalificarlo como un Acta válida de la nación, mediante la intercalación de un inciso escrito en el presente, que altera retroactivamente la percepción de los hechos.

Queremos hacer notar aquí las operaciones de lectura que realiza Bernardo Colipán con este documento. Luego de citarlo -en realidad, es un escueto informe mandado a la capital como telegrama-, Colipán lo lee ante nosotros, prestando atención a los hechos allí dispuestos; pero muy especialmente a las expresiones y modos de decir que modifican semánticamente el mensaje. Así argumenta ante nosotros, que nos constituimos como un gran tribunal:

Cabe subrayar el tono coloquial y reposado del gobernador, en el que demuestra con tranquilidad que la misión fue cumplida con toda la "prudencia" que demandaba la situación. Se menciona que en ningún caso existió una actitud desmedida de la fuerza pública, más bien actuaron conforme a las circunstancias que demandaba el "acto administrativo". Se reitera la templanza con la que se actuó, y todos los medios pacíficos que se agotaron ante un grupo de indígenas "que sólo deseaban morir" (Colipán y comunidad indígena de Forrahue s/n).

Colipán toma con pinzas palabras y expresiones - prudencia, acto administrativo, que sólo deseaban morir- que nos permiten inferir la retórica que sustenta este urgente telegrama; además de connotar varios contrarrelatos que hacen visible el heroico acto de resistencia de la comunidad de Forrahue, que debe ser reconocido por la nación chilena, aunque sea con retraso de cien años.

Por último, quiero referirme a la reconstitución de la escena insertando datos inéditos que surgen del relato oral familiar y comunitario que llega hasta nuestros días. Estos datos, referidos al destino de los cuerpos (los cadáveres) configuran la imagen vergonzosa de una nación, que este libro repara. La información, monda y desnuda, es la siguiente: tres niños fueron obligados a trasladar los cadáveres en carretas de bueyes (se han retenido los nombres propios de los tres); las autoridades prohibieron la entrada a la ciudad de Osorno a los comuneros, destino mortuorio de las carretas; los familiares nunca recuperaron los cuerpos, que fueron a dar a la fosa común. 
No habiendo sido enterrados, el sepulcro es el libro (que los saca del anonimato de la fosa común) y el lugar de la matanza en Forrahue (registrado en fotos actuales) tiene la posibilidad de transformarse en un santuario. ${ }^{8}$

\section{Genealogía de la vida: rojo flujo vital}

En las siguientes secciones reconocemos, primero, una dedicada a genealogías de vida, que son árboles genealógicos de uno de los asesinados (Antonio Nilián), de los dos sobrevivientes de la matanza (Pedro José Acum Paillán y Micaela Marrián Villarican), y de otra familia de comuneros cuyos nombres no aparecen en la fatídica lista oficial, pero que suponemos pertenece al grupo que resistió el desalojo. Estos árboles incluyen tres o cuatro generaciones, ubicándose los testigos de oídas de la actualidad en la tercera y cuarta generación. Hemos mencionado aquí la figura del árbol genealógico; pero los diagramas no exhiben aquella figura normal que semeja un árbol y sus ramas, sino que los nombres aparecen incluidos en semicírculos a modo de medialunas (figura 3).

Las páginas que soportan estas genealogías son de un color ladrillo rojizo. Sobre ellas se dibujan estos semicírculos sagrados. Asociamos el color de la página al rojo, que en la cultura mapuche es la fuerza que anima la sexualidad, así como señal de guerra y gestación. Es la sangre que fluye en su doble signo de germinación y herida. ${ }^{9} \mathrm{Y}$ es en este espacio donde

8 Como ya lo indicamos, este cementerio fue declarado monumento histórico en el año 2014. Faltaría allí un memorial que dé cuenta de la matanza, con los nombres de los comuneros asesinados, análogo al memorial por los desaparecidos en tiempos de la dictadura reciente en Chile, que está en el Cementerio General de Santiago, el cual lleva grabados unos versos del poeta Raúl Zurita. Hacemos constar que existe un parentesco entre los textos poéticos de Zurita y este libro sobre Forrahue, por cuanto a nivel simbólico se plantean como una experiencia de duelo y redención de un espacio que ha sido arrasado por una catástrofe. Anotemos de paso que la diagramación de Forrahue evoca la de los textos de Zurita, pues estos incluyen materiales diversos; por ejemplo, en Purgatorio, una copia de foto de carnet de identidad del autor, un electrocardiograma y, en la portada y contraportada, un pedazo de su rostro, que puede asimilarse a un paisaje. De modo suplementario, recordemos que Zurita ha apoyado con entusiasmo las creaciones de los poetas mapuches, ayudándolos a que editen sus obras en editoriales de visibilidad nacional y continental.

9 Para el significado de los colores en el mundo mapuche, referimos al texto "Colores aquí. Simbología mapuche del color", de Pedro Mege. De un modo sintético, de Kelü, fluido de vida y muerte, Mege nos indica lo siguiente: "El color rojo está referido básicamente a la sangre de diferentes tipos, y es dentro del dominio de la representación textil donde se 
se ensayan esas mitades de esferas que nos remiten al instrumento del cultrún, que tiene un timbal en cuyo paño cilíndrico se plasma una síntesis dialéctica del universo ${ }^{10}$ (figura 4 ). Al poner nuestros ojos en esos diagramas es como si accionáramos una caja de resonancia y nos incluyéramos en una ceremonia de sanación, imbuidos de su ritmo. ${ }^{11}$

Como el diseño gráfico del libro fue realizado por personas que no tienen nombres mapuches, podemos conjeturar que estas páginas ensayan espacios de interpenetración de lo mapuche en lo chileno, al modo de un blanqueamiento al revés. Conjeturamos que estamos en presencia de una apropiación estilizada de un sistema de representaciones vernáculas, como un modo de establecer hermandades simbólicas en el ámbito de un discurso nacional que quiere legitimarse desde el reconocimiento del otro. ${ }^{12}$

expresa parte fundamental de su significado, siendo aquí, sangre que fluye [...] . [V] estirse con prendas rojas o con motivos rojos es señal de poder, de la fuerza que da o quita vida y que se relaciona con dos dominios diferentes: lo femenino y lo masculino. Si el hombre ocasiona el fluir de la sangre, es el índice de su poder. Si emana de las entrañas de la mujer, también es el poder de lo femenino. La utilización de estos símbolos implica cargarse el cuerpo con signos tremendamente impresionantes y cruciales dentro de la visión mapuche: la fuerza que anima la sexualidad, las señales de la guerra y la gestación" (252-253).

"El kultrun o cultrún representa en la cosmovisión mapuche la mitad del universo o del mundo en su forma semiesférica; en el parche se encuentran representados los cuatro puntos cardinales, que son los poderes omnipotentes de Ngnechen dominador del universo, los cuales están representados por dos líneas a manera de cruz y sus extremos se ramifican en tres líneas más, representando las patas de choique (avestruz); dentro de los cuartos que quedan divididos por las líneas anteriormente descritas se dibujan las cuatro estaciones del año" (Pueblos originarios). Para una información acabada sobre este pequeño microcosmos simbólico, que encarna la propia madre-tierra, asegurando la comunicación, la cohesión y la solidaridad social, cf. María Ester Grebe.

11 Estos diagramas circulares nos evocan el espacio sagrado dispuesto en el fogón, lugar donde se funda el tiempo cotidiano con el de la memoria. El mismo Bernardo Colipán en su artículo ya citado "Identidades, memoria y alegorías" anota: "El koyagtún constituía el primer referente de socialización del niño. En torno al fogón, los ancianos (kimches) transmitían a las nuevas generaciones las historias y relatos de quienes los precedían. La experiencia de estar sentados en círculos en torno al fuego los situaba en una misma distancia uno del otro. Sus respectivos horizontes de percepción, siendo distintos, partían desde una misma distancia, las jerarquías, situadas en una relación de simetría, no dejaban de ser respetadas" (462).

12 Tenemos presente aquí, nuevamente, el principio dialógico bajtiniano, que distingue dos voces en un mismo discurso; voces que pueden ser divergentes o convergentes entre sí. En la estilización, el autor trabaja con el punto de vista de otro discurso, según su propio interés y objetivo. Así, los diagramadores de este libro utilizan el discurso mapuche para proponer un encuentro cultural entre dos visiones. A diferencia de la 


\section{Certificados de defunción: cuerpos visibles}

A estas genealogías le sigue una hoja con la lista oficial de muertos: bajo el título de Hermanos, se anotan los Asesinados (trece nombres), los Heridos y reos (los mismos trece nombres) y los Sobrevivientes, con dos nombres (figura 5). Suponemos que la nominación Heridos y reos es la de un parte oficial, que notifica el ingreso al hospital de estos comuneros, que luego aparecen muertos o ejecutados por un pelotón de carabineros; es decir, desde el discurso histórico presente, Asesinados. ${ }^{13}$

Como un modo de volver a visibilizar esos nombres sin sepultura, la siguiente sección incluye la foto de ocho certificados de defunción, siete de los cuales corresponden a los asesinados. Conjeturamos que el octavo daría cuenta de otros muertos que no aparecen en las listas oficiales (figura 6). Estos certificados diagramados en la página derecha vienen acompañados con la letra de una canción del grupo musical chileno Illapu Aunque los pasos toquen mil años, que puede asociarse a la memoria de los caídos en Forrahue (figura 6).

Los certificados de defunción de estas personas tienen fecha de emisión del 2 de septiembre del año 2011. Es decir, a 99 años de ocurrida la matanza, se les reedita legalmente, incluyendo estos certificados en un archivo renovado de la república, donde estos cuerpos se insertan desde un contexto valórico actual asociado a los Derechos Humanos. En este sentido, la cita de la canción del grupo folklórico Illapu -representante del folklore chileno ligado al gobierno de la Unidad Popular (1970-1973) y al exilio- señala un parentesco entre la situación vivida en Forrahue y las situaciones de represión vividas en la dictadura chilena.

Es una nueva certificación de los hechos, una puesta al día del archivo burocrático de la nación, una documentación que permite reinscribir en la memoria legal republicana un hecho traspapelado. Con estos certificados, cuyas páginas llevan plantificado el sello del escudo patrio de modo indeleble, y con los respectivos membretes y firmas de la administración pública, los ciudadanos chilenos de hoy recuperamos la memoria, leyendo

parodia, en la estilización el pensamiento del autor y el pensamiento del otro siguen en la misma dirección, produciéndose una convergencia (Todorov "Intertextuality").

13 Hay ciertas imprecisiones en la parte escrita del texto, referidas a nombres y cifras y, además, a aspectos de editing, que deberían corregirse en una segunda edición. Ahora bien, los diagramas están realizados con mucho rigor y la diagramación del libro -su sintaxis visual- tiene un fundamento estético y cultural de relevancia. 
por ejemplo que según consta en el número de inscripción 544 del año 1912, doña Ánjela Rauque Rauque falleció el 19 de octubre de 1912 a las o9:30 hrs. en Forrahue.

Esta certificación chilena de personas difuntas huilliches opera en la conciencia ciudadana chilena como el regreso de lo reprimido, reubicando en el centro de la pantalla de nuestra conciencia la pregunta sobre el despojo sufrido por las comunidades originarias.

\section{Voces reunidas, hilos de la voz}

La última sección del libro recoge los testimonios de ocho descendientes de la tercera y cuarta generación de los ejecutados y sobrevivientes de Forrahue. Aparecen las fotos de tres de los que dan testimonio, como prueba de realidad. Es como un levantamiento de datos fragmentados y dispersos, que entretejidos podrán otorgar una imagen común que permita la restitución de una memoria colectiva.

Estos dichos aparecen intersectados por Notas de campo fechadas en marzo y abril de 2011. Son anotaciones sobre memoria e identidad realizadas por el autor Bernardo Colipán en su función de investigador, a modo de intérprete de los materiales recogidos. Siguiendo la metáfora del telar, son hebras que van reforzando y realzando la asociación y figuración de diagramas e imágenes complejas y unitarias. Así, en una de estas Notas se dice: "Cuando no sabemos quiénes somos, seremos lo que se dirá de nosotros. La identidad provendrá de afuera" (Colipán y comunidad indígena de Forrahue s/n). Aclaremos que estas notas están también diseminadas a lo largo de todo el libro.

En su formato, estos testimonios aparecen diagramados como si formaran parte de un periódico popular o una revista de gremio producida artesanalmente. ${ }^{14}$ Los testimonios de cada uno aparecen subdivididos en breves historias presentadas por un titular, que retoma una de las frases emblemáticas del texto (figura 7). Algunos de estos titulares tienen una fuerte carga de poeticidad, como, por ejemplo: "Sólo quiero una flor, una vela siquiera un día"; y otros dan claras señas de las marcas de religiosidad popular en el mundo mapuche: "Me dejaron colgado de los pies, yo usaba

14 Estos testimonios en formato de noticias (en hojas sueltas) nos traen a la memoria la lira popular chilena, poesía en décima impresa en pliegos durante el último tercio del siglo XIX y las primeras décadas del siglo XX, referida a lo divino y a lo humano. También denominada en otros países literatura de cordel (cf. Memoria chilena). 
la estampa de la virgen de Montserrat". Hay titulares que enuncian de modo emblemático los olvidos del discurso republicano: "Carreteros de la muerte" y hay los que dan noticias de una resistencia constante en el tiempo a los despojos sufridos: "Hay quienes luchan muchos años".

Siendo la historia del pueblo mapuche una historia oral, que se transmite de generación en generación a través de diversas modulaciones (por ejemplo, la canción, el cuento, la adivinanza), estos testimonios surgen desde la oralidad, generando una escritura "contaminada" que se distancia de la cultura letrada y converge con otras prácticas populares chilenas basadas en el habla. ${ }^{15}$

Quiero nombrar finalmente un testimonio que se refiera a la función que ocupa este libro en la comunidad mapuche. José Domingo Nilián Hueituyao, de 78 años, originario de Putica, nos dice: "En este caso, como para hacer un libro, me parece bien y cuando esté hecho vuelva de nuevo a la comunidad, para tener con qué comprobar lo que narraron los antepasados, porque mañana o pasado, nosotros ya no vamos a estar" (Colipán y comunidad indígena de Forrahue s/n). Se trata de apropiarse del libro como signo occidental (al cual se está irremediablemente suscrito), utilizándolo para su propio arbitrio, lo cual amplía su registro de memoria; a la vez que esta nueva modalidad permite un diálogo con la cultura letrada y la tradición republicana fundada por don Andrés Bello.

\section{Imágenes del olvido}

A modo de epílogo, aparece una fotografía de una cruz que se precipita en medio de unos pastizales o sitios abandonados a la buena de Dios (figura 8). Son fotos artísticas, un trabajo muy elaborado que testimonia el reclamo por una digna sepultura en un espacio sagrado que aparece hoy mancillado. Este mensaje es reforzado con la leyenda "El olvido es la muerte", ocupando cada una de las partes de la oración (el sujeto, la cópula verbal y el predicado) una página entera, acompañando las fotografías

15 El poeta Elicura Chihuailaf ha creado una palabra que fusiona la oralidad con la cultura letrada, infartando la literatura de oralidad; es la palabra oralitura: "Nuestra historia sigue siendo una historia oral y, por lo tanto, si se va a abordar desde el punto de vista mapuche, tendrá que serlo desde lo que denominamos 'oralitura', que constituye una búsqueda, un atisbo de respuesta. Se trata de una escritura que está respondiendo al pensamiento de nuestra gente, a nuestra memoria y, por ende, implica asumir la validez predominante que tiene para nosotros la oralidad" (550). 
a modo de una Nota de campo. Epílogo que continúa el trenzado cultural hacia adentro, hacia lo íntimo, añadiendo una hebra más al registro fotográfico de la portada y contraportada, mostrando su revés.

Este registro nos evoca esos cementerios judíos abandonados en varios pueblos de Europa del este durante la segunda mitad del siglo XX, cuyas tumbas están destruidas o han desaparecido entre la maraña de plantas silvestres. ${ }^{16}$ Cementerios borrados, o también villorrios suspendidos o cambiados de lugar y cuerpos anónimos enterrados en bosques vecinos o en cementerios locales de los alrededores, sin marca que los distinga, salvo la de la negación. Y en el límite de la vergüenza, campos de concentración como si fueran una cosa natural, unas barracas en medio de unas tierras que todos ignoran, sin que se delimite su espacio; se lo purifica, se lo devuelve a lo humano.

\section{Hubo una vez un libro...}

A la hora de las conclusiones proponemos que este libro es un artefacto cultural que cumple una función simbólica de reparación de un colectivo. En su imagen textil, es una obra que conecta los diversos fragmentos (hebras), conformando una figura indivisa, que recupera el cuerpo mapuche deshilachado. A nivel histórico, es un archivo que se agrega de modo privilegiado a la biblioteca letrada de la comunidad mapuche, en tanto trabaja lo vivido desde registros que privilegian los lazos primordiales. Opera también como un escrito legal, cuyas crónicas, certificados y testimonios de oídas conforman un escrito legal de carácter probatorio ante la justicia. Y, por último, en un ámbito simbólico amplio, este libro es un sepulcro donde reposan dignamente los cuerpos de los comuneros asesinados, lo cual permite que se cumpla el luto. Por extensión, mediante el registro fotográfico, esta obra mantiene en la memoria el lugar físico de Forrahue, el espacio donde los comuneros murieron, el lugar donde debieron haber sido enterrados. El libro es entonces, también, ese espacio natural que nos

16 Evocamos aquí el testimonio de Tzvetan Todorov acerca de una visita no planificada al cementerio judío de Varsovia, un domingo de noviembre de 1987, en medio del coloquio sobre monumentos al cual asistía: "Estábamos solos. Apenas habíamos dejado la avenida central cuando nos hundimos en un follaje indescriptible: las copas de los árboles cubrían las tumbas, los yerbajos las habían invadido borrando sus límites; las lápidas estaban a su vez hundidas en la tierra, pegadas a los sarcófagos. Se podía discernir, por contraste, que los demás cementerios eran lugares de vida, puesto que el pasado seguía presente en ellos, mientras que aquí, las tumbas, petrificación del recuerdo, morían una tras otra" (Frente al límite 12). 
acompaña visualmente en nuestra lectura. Ahora bien, si recordamos que hacia el año 2014 el lugar físico de Forrahue fue declarado monumento histórico nacional, erigiéndose como un sitio de visita, recogimiento y peregrinación, entonces concluimos que ha sido un libro el que ayudó a refundar el espacio natural comunitario mapuche y chileno. Hubieron de pasar 100 años para que el despojo fuera visible a los ojos republicanos y estas osamentas fueran reconocidas como parte de nuestra matriz.

\section{Obras citadas}

Alcamán, Eugenio. "Las ideas de identidad e historia en una región multiétnica". Revisitando Chile. Identidades, mitos e historia. Comp. Sonia Montecino. Santiago: Cuadernos Bicentenario, 2003. 442-449. Impreso.

Bengoa,José. "Encontrando la identidad en la celebración de la diversidad". Revisitando Chile. Identidades, mitos e historia. Comp. Sonia Montecino. Santiago: Cuadernos Bicentenario, 2003. 600-607. Impreso.

Chihuailaf, Elicura. "Nada que celebrar y mucho que conversar". Revisitando Chile. Identidades, mitos e historia. Comp. Sonia Montecino Santiago: Cuadernos Bicentenario, 2003. 549-553. Impreso.

Colipán, Bernardo. "Identidades, memoria y alegorías". Revisitando Chile. Identidades, mitos e historia. Comp. Sonia Montecino. Santiago: Cuadernos Bicentenario, 2003. 457-462. Impreso.

Colipán, Bernardo y comunidad indígena de Forrahue. Forrahue. Matanza de 1912. Osorno: s/e, 2012. Impreso.

Consejo de Monumentos Nacionales de Chile. "Forrahue, matanza de 1912". http://www.monumentos.cl/catalogo/625/w3-article-39481.html. Web.

Foerster, Rolf. "El movimiento mapuche y las instituciones mediadoras". Revisitando Chile. Identidades, mitos e historia. Comp. Sonia Montecino. Santiago: Cuadernos Bicentenario, 2003. 416-423. Impreso.

Geertz, Clifford. La interpretación de las culturas. Barcelona: Gedina, 2013. Impreso. Grebe, María Ester. "El kultrun mapuche: un microcosmo simbólico". Revista Musical Chilena 27.123-1 (Santiago, julio-diciembre de 1973): 3-42. Impreso. Mege, Pedro. "Colores aquí. Simbología mapuche del color". El lenguaje de los dioses. Arte, chamanismo y cosmovisión indígena en Sudamérica. Eds. Ana María Lamazares y Carlos Martínez Saraola. Buenos Aires: Biblos, 2004. 247-257. Impreso. Memoria chilena. "Lira popular". www.memoriachilena.cl/602/w3-article-723.htlm. Web. Museo de Arte Preocolombino. "Piezas selectas, el kultrún". http:// chileprecolombino.cl/arte/piezas-selectas/el-kultrunc. Web. 
Pueblos originarios. "Kultrún".http//www.pueblosoriginarios. com/sur/Patagonia/mapuche/kultrun.htm/. Web.

Todorov, Tzvetan. Frente al límite. México: Siglo XXI editores, 2013. Impreso.

Todorov, Tzvetan. "Intertextuality". Mikhail Bakhtin. The Dialogical Principle. Minneapolis: University of Minnesota Press, 1984. 60-74. Impreso.

Zurita, Raúl. Purgatorio. Santiago: Universitaria, 1979. Impreso. 